\title{
Expression and Localization of Epithelial Aquaporins in the Adult Human Lung
}

\author{
Silvia M. Kreda,* Michael C. Gynn,* David A. Fenstermacher, Richard C. Boucher, and Sherif E. Gabriel \\ Cystic Fibrosis/Pulmonary Research and Clinical Treatment Center, University of North Carolina at Chapel Hill, \\ Chapel Hill, North Carolina
}

\begin{abstract}
Aquaporins (AQPs) facilitate water transport across epithelia and play an important role in normal physiology and disease in the human airways. We used in situ hybridization and immunofluorescence to determine the expression and cellular localization of AQPs 5, 4, and 3 in human airway sections. In nose and bronchial epithelia, AQP5 is expressed at the apical membrane of columnar cells of the superficial epithelium and submucosal gland acinar cells. AQP4 was detected in basolateral membranes in ciliated ducts and by in situ in gland acinar cells. AQP3 is present on basal cells of both superficial epithelium and gland acinus. In these regions AQPs 5, 4, and 3 are appropriately situated to permit transepithelial water permeability. In the small airways (proximal and terminal bronchioles) AQP3 distribution shifts from basal cell to surface expression (i.e., localized to the apical membrane of proximal and terminal bronchioles) and is the only AQP identified in this region of the human lung. The alveolar epithelium has all three AQPs represented, with AQP5 and AQP4 localized to type I pneumocytes and AQP3 to type II cells. This study describes an intricate network of AQP expression that mediates water transport across the human airway epithelium.
\end{abstract}

Water transport across pulmonary epithelia is a vital component of lung physiology. In proximal airways, transepithelial water movement replaces insensible water loss; in the perinatal period, water is reabsorbed across the alveolar epithelium during the transition from fetal to ex utero life; and in all airway regions, transepithelial water flux is responsible for maintenance of an isotonic airway surface liquid (ASL) (1-8). Water transit across cell membranes can be measured in terms of the coefficient of osmotic water permeability $\left(\mathrm{P}_{\mathrm{f}}\right)$ with the direction of flow determined by the orientation of the osmotic gradient $(9,10)$. Perhaps the most direct measurement of $\mathrm{P}_{\mathrm{f}}$ was made in guinea-pig distal airway, which exhibited a $\mathrm{P}_{\mathrm{f}}$ value of 4 to $5 \times 10^{-3}$ $\mathrm{cm} / \mathrm{s}$. Biophysical studies in whole-lung preparations of sheep and mouse have also quantified a relatively high $\mathrm{P}_{\mathrm{f}}$ of $7.0 \times 10^{-2} \mathrm{~cm} / \mathrm{s}$ across alveolar epithelial barriers (812). Such high $P_{\mathrm{f}}$ is consistent with transcellular water flow through molecular water channels, aquaporins (AQPs) (710). These permeabilities are comparable with $P_{f}$ values measured in proximal convoluted segments of renal tubu-

(Received in original form September 13, 2000 and in revised form November 22, 2000)

*These authors contributed equally to this manuscript.

Address correspondence to: Sherif E. Gabriel, Ph.D., CF/PRT Center \& Dept. of Pediatrics, 6007 Thurston Bowles, University of North Carolina, Chapel Hill, NC 27599-7248. E-mail: sgabriel@med.unc.edu

Abbreviations: airway surface liquid, ASL; aquaporin, AQP; complementary DNA, cDNA; hematoxylin and eosin, H\&E; immunofluorescence, IF; immunoglobulin, Ig; in situ hybridization, ISH; messenger RNA, mRNA; water permeability, $\mathrm{P}_{\mathrm{f}}$; surfactant protein, $\mathrm{SP}$.

Am. J. Respir. Cell Mol. Biol. Vol. 24, pp. 224-234, 2001

Internet address: www.atsjournals.org lar epithelium (mainly AQP1) and distal collecting ducts (AQP2), where the antidiuretic function of AQPs in normal physiology and disease are well established $(8-10,13)$.

AQPs are integral membrane proteins that function as molecular water channels in a variety of fluid transporting tissues. To date 10 mammalian AQP proteins, AQP0 to AQP9, have been identified $(8-10,13)$. AQP isoforms have a distinctive tissue distribution and cellular expression pattern (e.g., apical versus basolateral membrane in epithelia) and permit rapid and specific water transport in response to osmotic gradients. Immunocytochemistry and messenger RNA (mRNA) expression studies of AQPs have revealed that only four of the known AQPs are present in the rodent airway (14). AQP1 is abundantly expressed in the plasma membrane of endothelial cells of the microvasculature and visceral pleura. AQP5, a mercury-sensitive water channel, has been found primarily in the apical membrane of type I alveolar pneumocytes and submucosal gland acinar cells in the upper airways. AQP4, a non-mercury sensitive water channel, has been localized to the basolateral membrane of columnar cells in the superficial epithelium lining the upper airways. AQP3, a water channel that has a high permeability for glycerol, appears to be expressed predominately in the plasma membrane of basal cells in the proximal airways (tracheal region) $(8-10,13,14)$. This discrete, predominately nonoverlapping distribution suggests a functional specialization for AQPs in different regions of the mammalian airways. Interestingly, no AQPs have yet been identified in three airway locations important for lung fluid homeostasis: (1) the apical membrane of bronchial epithelia; (2) small airways, both psuedostratified and simple cuboidal bronchiolar epithelia; and (3) the basolateral membrane of type I alveolar cells or in either membrane of type II pneumocytes.

In spite of the recognized role of ASL in human airway diseases and the fundamental contribution of AQPs to the homeostasis of the ASL, few studies have addressed water permeation (or AQP function) across human airway epithelia. Previous studies in human nasal and bronchial cultured cells revealed high $P_{f}$ across these epithelia suggesting a role for AQPs, but did not search for specific AQPs to account for these permeabilities $(1,6)$. The present study examines the tissue distribution and cellular localization of the reported lung epithelial AQPs, i.e., AQP3, AQP4, and AQP5 in the human respiratory tract. We used in situ hybridization (ISH) and immunofluorescence (IF) studies of nasal epithelia and different caliber intrathoracic airway segments, and determined expression in lumenal, glandular, and alveolar epithelia. Our findings reveal extensive AQP distribution in airway and air-space epithelia, suggesting that AQP3, AQP4, and AQP5 play a significant role in 
the network of water channels that mediate water conductance in the human lung.

\section{Materials and Methods Tissue Acquisition}

Human nasal sections were obtained from patients undergoing rhinologic procedures (e.g., turbinectomy). Upper and lower airways were obtained from excess tissue from donor lungs of patients involved in lung transplantation. All human tissue protocols were reviewed and approved by the University of North Carolina Committee for the Protection of the Rights of Human Subjects. Tissues were rapidly dissected from several regions (bronchi, trachea, bronchioles, and alveolar epithelia) and freshfrozen directly in OCT embedding compound, typically within 30 min of tissue resection. Distal airway sections were frozen after OCT freezing media inflation. Tissue blocks were stored at $-80^{\circ} \mathrm{C}$ until used for ISH or IF studies. For these studies, thin sections (6 to $10 \mu \mathrm{m})$ were cut by a cryothome, mounted on glass slides, and stored at $-80^{\circ} \mathrm{C}$ until analysis by either ISH or IF.

\section{Airway Classification}

Intrathoracic respiratory segments were classified into three categories according to histologic features: (1) the relatively large diameter and presence of cartilage and mucosal glands subjacent to a pseudostratified lumenal epithelium defined bronchi or "large airways"; (2) bronchioles or "small airways" were characterized as noncartilagenous and aglandular airways lined with pseudostratified epithelium (proximal bronchioles) or simple cuboidal epithelium (terminal bronchioles); and (3) the alveolar compartment.

\section{Human Complementary DNA Library Construction and Screening}

Trachea and third- to sixth-generation airways were dissected from a human lung donor tissue sample and incised longitudinally. Guanidine thiocyanate was applied directly to the surface epithelium for 1 to $2 \mathrm{~min}$ and the epithelial digest was removed by scraping the surface with a glass slide. RNA was isolated by $\mathrm{CsCl}$ centrifugation and confirmed by gel electrophoresis. Microscopic examination of the tissue sections established that the superficial epithelium was effectively removed from the underlying structure. Isolated RNA was reverse transcribed and a complementary DNA (cDNA) library was constructed using the ZAPcDNA Synthesis Kit (Stratagene, La Jolla, CA) as previously described. Two oligonucleotide probes were designed targeting consensus sequences for the mercury-sensitive region of the known AQP: oligonucleotide \#1, 5'-T(A/T)C AC(T/C) GGC TG(T/C) TC(T/C) ATG AA(T/C) CC(A/T) GC(T/C) CG(G/C) TC-3'; and oligonucleotide \#2, 5'-T(A/T)C AC(T/C) GGC TG(T/C) GGG ATT $\mathrm{AA}(\mathrm{T} / \mathrm{C}) \mathrm{CC}(\mathrm{A} / \mathrm{T}) \mathrm{GC}(\mathrm{T} / \mathrm{C}) \mathrm{CG}(\mathrm{G} / \mathrm{C}) \mathrm{TC}-3^{\prime}$. The probes were radiolabeled and the cDNA library was screened under stringent conditions $(0.1 \times$ saline sodium citrate, $0.1 \%$ sodium dodecyl sulfate [SDS] at $\left.50^{\circ} \mathrm{C}\right)$. Positive clones were released by in vivo phage excision and sequenced by chain-termination automated sequencing.

\section{Northern Blot Analysis}

Total RNA was isolated from superficial epithelium of large airways or from whole-lung specimens obtained as described earlier. Total RNA, $10 \mu \mathrm{g}$, was resolved on a formaldehyde agarose gel and transferred to nylon membranes according to manufacturer's protocols. Hybridization was performed at high stringency with $\left[\alpha^{32} \mathrm{P}\right]$ deoxycytidine triphosphate (dCTP)-radiolabeled probes corresponding to AQP5, AQP4, and AQP3 coding sequences (see the following section). Blots were visualized by autoradiography, and $18 \mathrm{~S}$ and $28 \mathrm{~S}$ ribosomal bands were visualized by methylene blue staining.

\section{ISH}

Cryosections were fixed in $4 \%$ paraformaldehyde for $1 \mathrm{~h}$, dehydrated through a graded ethanol series, air-dried, and treated with $10 \mu \mathrm{g} / \mathrm{ml}$ proteinase $\mathrm{K}$ at $30^{\circ} \mathrm{C}$ for $30 \mathrm{~min}$. Tissue sections were incubated in prehybridization buffer (10 mM Tris [pH 8], $50 \%$ formamide, $2.5 \times$ Denhardt's solution, $0.6 \mathrm{M} \mathrm{NaCl}, 1 \mathrm{mM}$ ethylenediaminetetraacetic acid, $0.1 \%$ SDS, $500 \mu \mathrm{g} / \mathrm{ml}$ transfer RNA, and $10 \mathrm{mM}$ dithiothreitol) at $54^{\circ} \mathrm{C}$ for $4 \mathrm{~h}$ and hybridized at $54^{\circ} \mathrm{C}$ for $18 \mathrm{~h}$ with $\mathrm{AQP}$-specific probes. ${ }^{35} \mathrm{~S}$-uridine triphosphate- and ${ }^{35} \mathrm{~S}-\mathrm{CTP}-$ labeled sense or antisense riboprobes, containing at least $10^{7}$ counts per $\mathrm{min} / \mathrm{ml}$, corresponding to the coding sequence of AQP5 (base pairs [bp] 156-905), AQP4 (bp 156905), and AQP3 (bp 139-932) were made with $T_{7}$ or $T_{3}$ RNA polymerase. After washing and ribonuclease treatment, tissue sections were exposed to photographic emulsion for 7 to $10 \mathrm{~d}$. Sections were counterstained with hematoxylin and eosin (H\&E) for light microscopic examination. A Nikon microphot SA microscope connected to a 3CC-Chilled Camera (Sony, Marietta, GA) and interfaced to a powerMac 8100 were used to capture the images via AdobePhotoshop.

\section{IF}

Antibodies. A polyclonal antibody to AQP5 was generated against the synthetic peptide $\left(\mathrm{NH}_{2}\right.$-CWEDHREERKKTILTA$\mathrm{COOH}$ ) corresponding to the carboxy terminal 16 amino acids of the human AQP5. The peptide was crosslinked to keyhole limpet hemocyanin (UNC Peptide Synthesis Facility, Chapel Hill, NC) and injected into New Zealand White rabbits (Bethyl Corp., Montgomery, TX). Polyclonal anti-AQP5 immunoglobulin (Ig) G was purified from serum using affinity chromatography. Affinity-purified, peptide-derived antibodies against AQP4 and AQP3 were generously provided by Dr. Mark Knepper (National Institutes of Health, Bethesda, MD) and have been previously described $(15,16)$.

Primary antibody (source, dilution). Affinity-purified human AQP5 (Bethyl; 1/50-1/100 dilution); rat AQP5 (Chemicon, Temecula, CA; 1/100-1/200); rat AQP3 (Dr. M. Knepper; 1/75); rat AQP3 (Chemicon; 1/100-1/200); rat AQP4 (Dr. M. Knepper; 1/50-1/200, two different AQP4s synthesized by Dr. Knepper were independently tested); rat AQP4 (Chemicon; 1/50-1/200); rat pro-surfactant protein (SP) C (Dr. J Whitsett, University of Cincinnati, Cincinnati, $\mathrm{OH} ; 1 / 150$ dilution) (17).

\section{Immunohistochemistry}

Frozen tissue sections were fixed in $4 \%$ paraformaldehyde at room temperature for $4 \mathrm{~min}$. Tissue was permeablized in $100 \%$ ethanol at $-20^{\circ} \mathrm{C}$ (4 min) followed by blocking in $20 \%$ goat serum in $50 \mathrm{mM}$ sodium phosphate ( $\mathrm{pH} \mathrm{7.4)}$ and $150 \mathrm{mM} \mathrm{NaCl}$ for $3 \mathrm{~h}$. Tissue sections were incubated in primary antiserum (described later) or pooled normal rabbit IgG diluted 1:50 in phosphate-buffered saline (PBS) for $16 \mathrm{~h}$ at $4^{\circ} \mathrm{C}$. The tissue was washed in PBS and incubated with Texas Red-conjugated goat antirabbit IgG (Jackson ImmunoResearch, West Grove, PA) for $1 \mathrm{~h}$ at room temperature (specific signal stains red). Tissues were mounted in Vectashield containing 4,6-diamidino-2-phenylindole to label nuclei blue (Vector Laboratories, Burlingame CA). Photomicrographs were taken using a Leica TCS 4D confocal microscope at powers indicated in the figure captions. In some instances, a Leica DMIRB epifluorescence microscope connected to a 3CC-Chilled Camera (Shamamatsu, Raleigh, NC) was used to examine tissue sections. All images were captured and analyzed using AdobePhotoshop and MetaMorph (Universal Systems, West Chester, PA) imaging programs.

\section{Acquisition and Analysis of Data}

AQP ISH and immunostaining studies were performed in duplicate or triplicate using tissues obtained from different donors for each replicate. In most experiments, ISH and immunostaining 
were performed in parallel on the same histologic tissue block obtained from each lung region. Repeat experiments would then use a different tissue block (different donor, same region) to confirm ISH and immunostaining results. Three researchers independently scored the level of AQP expression and determined cell identification and intracellular localization for each AQP in each lung section studied. Acquired images are representative of all the tissue sections examined during these studies.

\section{Results}

Human cDNA Library Screening and Northern Analysis

Screening the human cDNA lung epithelial library with oligonucleotide primers designed to identify mercury-sensitive water channels yielded greater than 100 positive clones. AQP5 was identified 59 times and AQP1 was identified four times. A total of 24 miscellaneous, nonspecific genes were cloned; 14 previously uncloned genes were also identified. None of these, however, had any homology to known AQP sequences.
On the basis of these cloning results we proceeded to evaluate the expression and localization of AQP5 in the human airways. Northern blot analysis of total RNA from whole human lung showed a single prominent band at 1.6 $\mathrm{kb}$, corresponding to the previous reported length of the AQP5 transcript (18). Various animal models of AQP expression and function have demonstrated the presence of AQP4 and AQP3 in the airways. We therefore included AQP4 and AQP3 in our analysis of human airway AQP. Northern blots of RNA derived from the superficial epithelium of human large airways detected single unique bands of the appropriate size for both AQP4 $(\approx 1.2 \mathrm{~kb})$ and AQP3 (1.2 kb). Polymerase chain reaction fragments generated from these two products were sequence-analyzed and confirmed the identity of AQP4 and AQP3, respectively (data not shown). Although we did detect AQP1 expression in our library screen we chose not to evaluate this AQP because it has been shown to have predominately an endothelial expression pattern in the lung.

A
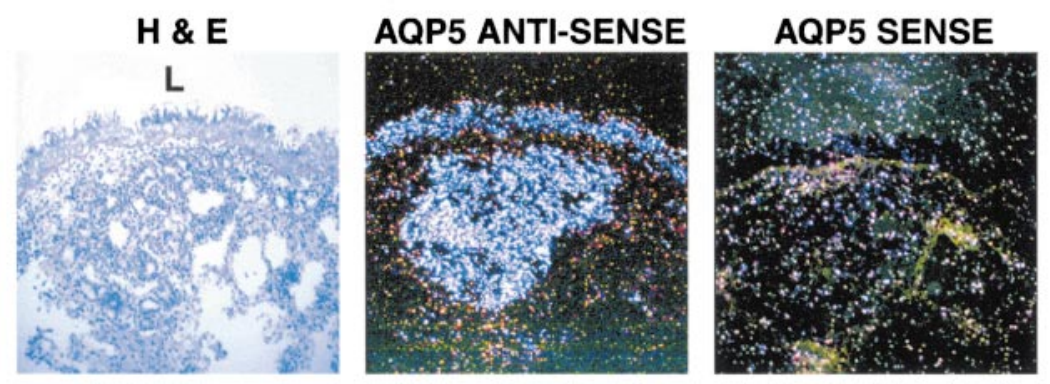

B

SUPERFICIAL EPITHELIUM
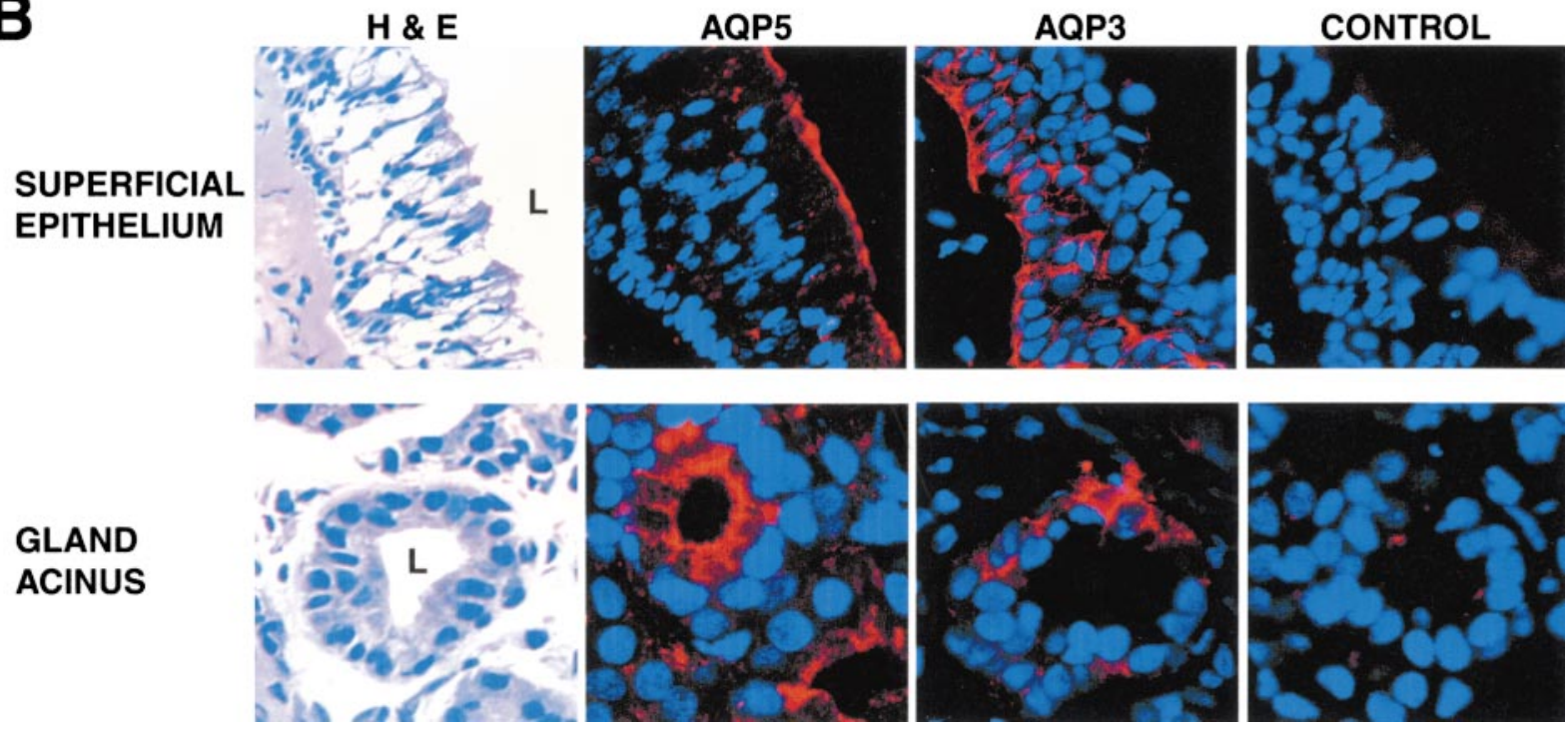

Figure 1. Expression of AQP5 and AQP3 in human nasal epithelium. (A) In situ hybridization of AQP5 in nasal tissue. Left panel corresponds to a brightfield (H\&E) nasal tissue section incubated with the AQP5 antisense probe. Center and right panels are darkfields of consecutive tissue sections hybridized with AQP5 antisense and sense ${ }^{35}$ S-labeled probes, respectively. Hybridization conditions, photographic emulsion exposure, and image acquisitions were identical for both probes. Original magnification: $\times 100$. $(B)$ IF of AQP5 and AQP3 in nasal epithelium (upper panel: superficial epithelium; lower panel: gland acinus). Left images are stained with H\&E, second images are sections stained with AQP5 antibodies, third images are sections immunostained with antibodies against rat-AQP3, and right images correspond to consecutive sections incubated with a nonimmune rabbit $\mathrm{IgG}$ (Control). Immunofluorescence images were acquired by $x y$ confocal scanning microscopy $(z \sim 1 \mu \mathrm{m})$. Original magnification: $\times 800$ (upper panel), $\times 1,500$ (lower panel). In this and all subsequent figures, $\mathrm{L}$ indicates lumen. 


\section{Nasal Tissue}

ISH with AQP5 antisense riboprobes revealed a discrete pattern of expression in nasal epithelium. AQP5 hybridization revealed robust mRNA expression in the superficial epithelium (Figure 1A). Strong signal was also present in clusters of subepithelial glands, where the signal was confined to acinar structures. Similar tissue sections were studied by IF using two antibodies directed against the $\mathrm{C}$-terminus of AQP5. Both antibodies generated strong immunoreactivity signals at the apical membrane of all columnar cells facing the lumenal surface of the superficial epithelium, and also at the apical membrane of serous cells in all the submucosal gland acini (Figure 1B). Strong expression of AQP3 was also observed in the superficial nasal epithelium by IF (third column in both rows of Figure 1B). The distribution of AQP3 appeared to be localized to the plasma membrane of all basal cells in the superficial epithelia, as well as the basal cells of some serous gland acini. Nonimmune controls were negative.

Expression of AQP4 was not detected in nasal epithelia either by ISH or by IF analyses, using several different antibodies and several different immunostaining techniques.

\section{Bronchi}

ISH studies of AQP5 in human bronchial tissue revealed prominent expression in the superficial epithelium and in submucosal glandular epithelium in the acinar portion of the glands (Figure 2A). No signal was seen in cartilaginous, vascular, interstitial, or any other cell types, and the sense riboprobe showed no signal above background. AQP5 IF was not routinely detected in the superficial epithelium. IF analysis of the same bronchial tissues showed specific AQP5 signal in the apical membrane of ciliated duct columnar cells, as well as at the apical membrane of serous cells in submucosal gland acini (Figure 2B). Nonimmune controls were negative.

ISH with an AQP4 riboprobe showed a mRNA expression pattern similar to that of AQP5, i.e., pronounced signal in both superficial and submucosal epithelium (Figure 3A). AQP4 expression was strongest in the submucosal glands where the signal was confined to the acini, and expression was less distinct although clearly present in the superficial epithelium. IF studies were unable to detect AQP4 immunoreactivity in the superficial or glandular epithelium. We did, however, observe AQP4 immunostaining in the ba-
A
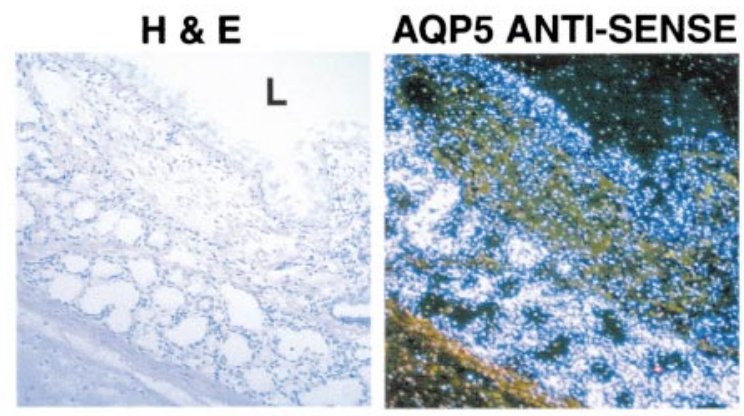

B
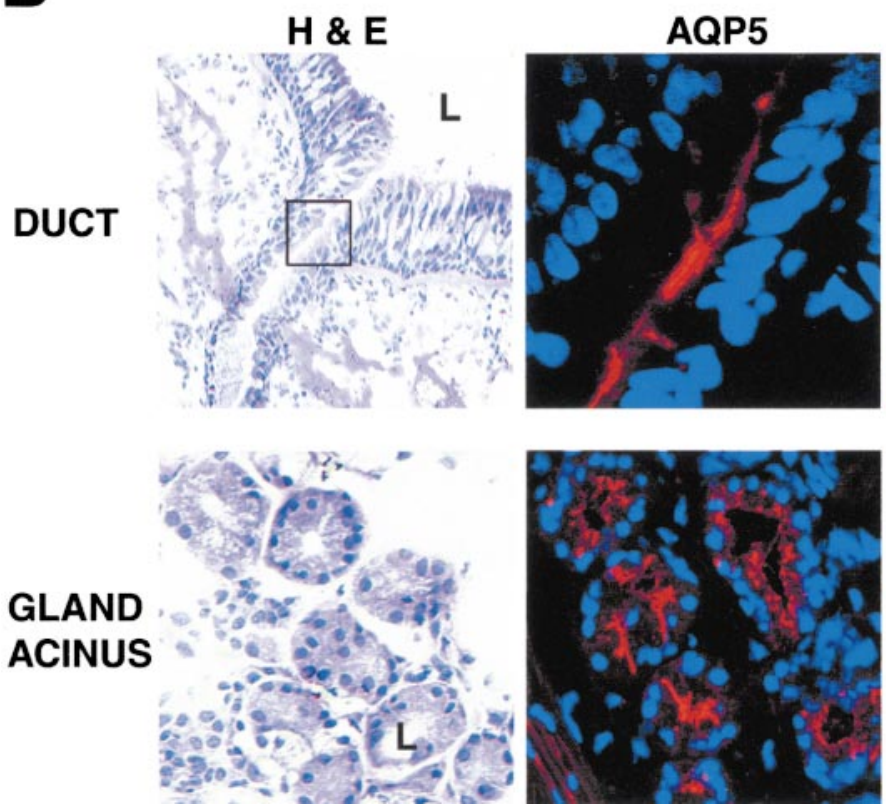

\section{AQP5 SENSE}

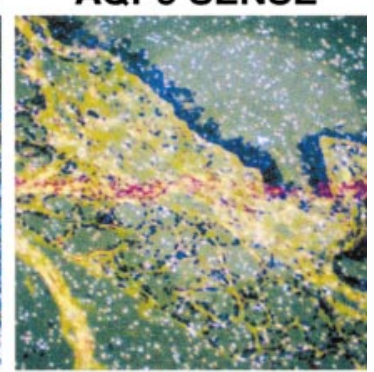

CONTROL
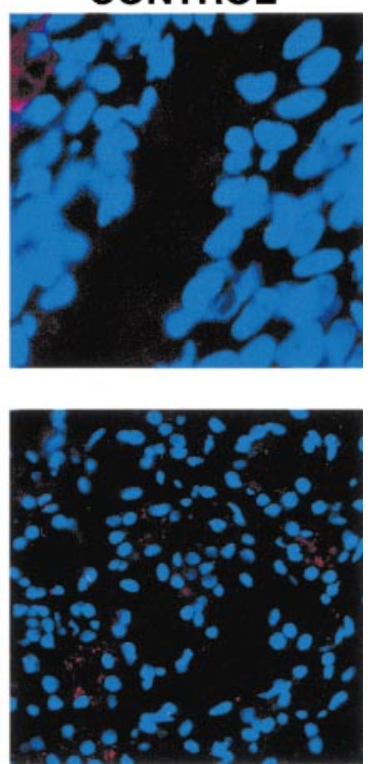

Figure 2. AQP5 expression in human bronchus. $(A)$ In situ hybridization of AQP5 in bronchial epithelium. All three images are consecutive tissue sections; left is an $\mathrm{H} \& \mathrm{E}$ brightfield; middle and right images represent sections hybridized by AQP5 antisense and sense probes, respectively. Original magnification: $\times 100$. $(B)$ AQP5 immunostaining in large ciliated ducts (upper panel) and gland acini (lower panel). A box is drawn in the H\&E upper panel to indicate the area that is magnified after AQP5 antibody (middle image) and control staining (right image). IF images were acquired by $x y$ confocal scanning microscopy $(z \sim 1 \mu \mathrm{m})$. Original magnifications: upper panel, $\times 250(\mathrm{H} \& \mathrm{E})$ and $\times 1,500$ (AQP5 and Control); lower panel, $\times 600$. 
A
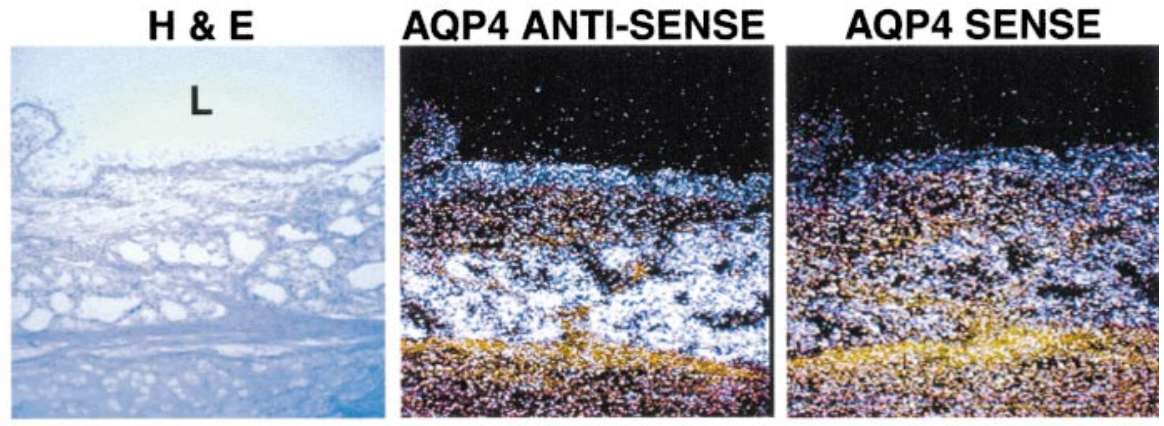

B
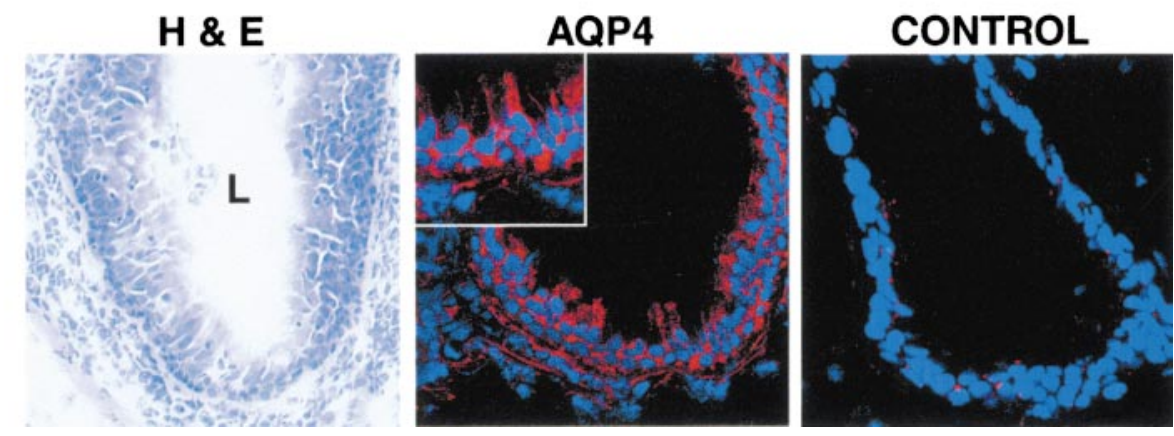

Figure 3. AQP4 expression in human bronchus. $(A)$ In situ hybridization of AQP4 in bronchial epithelium. All three images are consecutive tissue sections; left is an $\mathrm{H} \& \mathrm{E}$ brightfield; middle and right images represent sections hybridized by AQP4 antisense and sense probes, respectively. Original magnification: $\times 100$. $(B)$ AQP4 immunostaining in the basolateral membranes of columnar and intermediate cells of large ciliated ducts. The inset in the middle panel is an enlarged area showing AQP4 staining on the lateral membranes of columnar cells. IF images were acquired by $x y$ confocal scanning microscopy $(z$ $\sim 1 \mu \mathrm{m})$. Original magnification: $\times 400$; inset, $\times 600$.

solateral membrane of columnar and intermediate cells of ciliated ducts (Figure 3B).

AQP3 ISH signal was localized to the lower compartment of the pseudostratified superficial epithelia of bronchi (Figure 4A). AQP3 mRNA expression was absent from proximal portions of ducts and acinar regions of bronchial submucosal glands. No hybridization signal was seen in other cell types, and sense riboprobes displayed no specific signal above background. IF studies confirmed that AQP3 was highly expressed in the plasma membrane of all basal cells
A
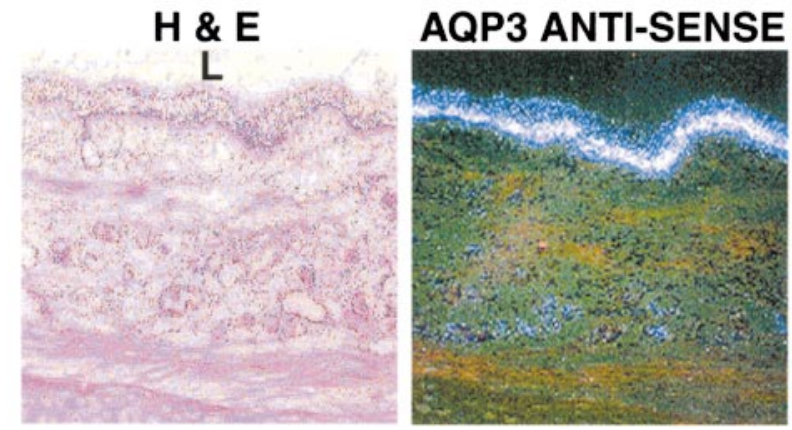

B

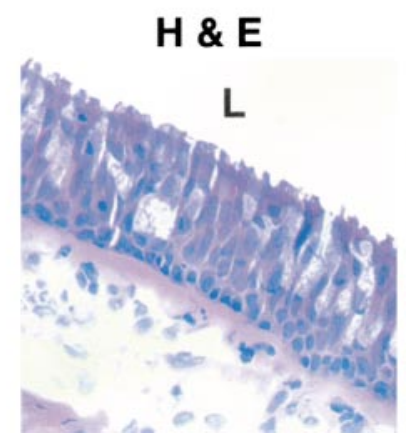

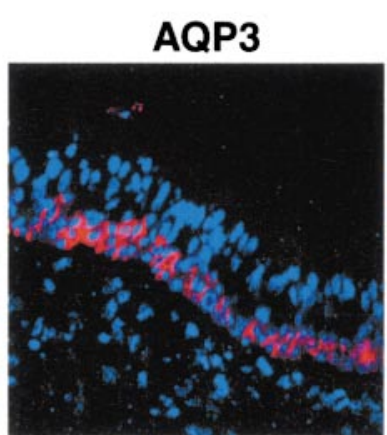

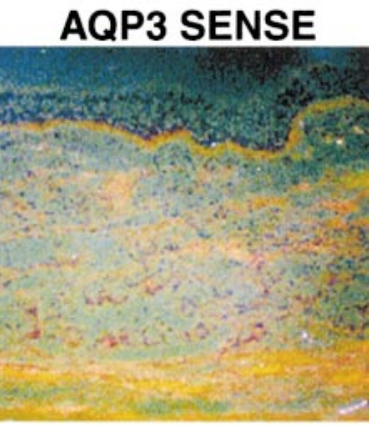

CONTROL

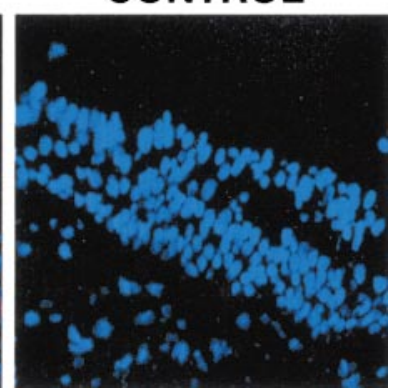

Figure 4. AQP3 expression in human bronchus. $(A)$ In situ hybridization of AQP3 in bronchial epithelium. Left image is an $\mathrm{H} \& \mathrm{E}$ brightfield; middle and right images represent sections hybridized by AQP3 antisense and sense probes, respectively. Original magnification: $\times 100$. $(B)$ Immunostaining with rat-AQP3 antibody in the membranes of the basal cells of bronchial epithelium. Original magnification: $\times 400$. 
in the human bronchi (Figure 4B). AQP3 immunolabeling was not observed in columnar epithelia or any other cell type. Nonimmune controls confirmed specificity.

\section{Bronchioles}

Of the three AQPs evaluated, only AQP3 displayed significant expression in human bronchiolar tissue. ISH analysis showed a strong signal in the superficial epithelia (basal cells) of pseudostratified, proximal bronchioles (Figure 5A). IF corroborated AQP3 presence in all the basal cells in this airway segment with intense labeling in the plasma membrane of these cells (Figure 5B). Surprisingly, robust AQP3 immunoreactivity was also observed at the apical membrane of all the columnar cells facing the lumen (Figure 5C).
In terminal bronchioles, AQP3 ISH revealed extensive expression in the simple cuboidal epithelium (Figure 6A). IF confirmed the expression of AQP3 protein (Figure 6B). Confocal microscopy revealed AQP3 immunostaining at the apical and basolateral membranes of the cuboidal epithelium (Figure 6C). No signal was detected with antibodies against AQP5 or AQP4 throughout the bronchiolar region, confirming the absence of signal by ISH for these AQP. Nonimmune controls were negative.

\section{Alveoli}

ISH studies demonstrated that all three AQPs-AQP5, AQP4, and AQP3 - were expressed in the alveoli. AQP5 ISH showed diffuse staining along alveolar cells with no

\section{A}

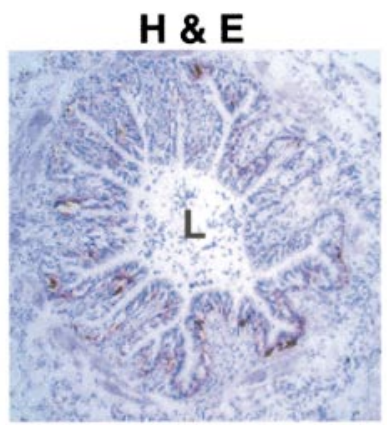
AQP3 ANTI-SENSE

\section{AQP3 SENSE}

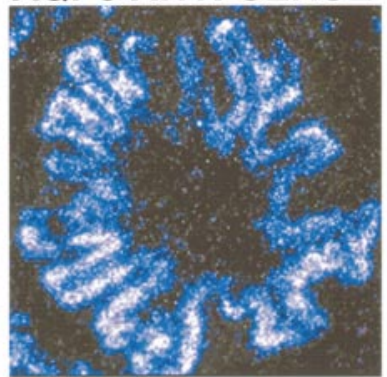

B
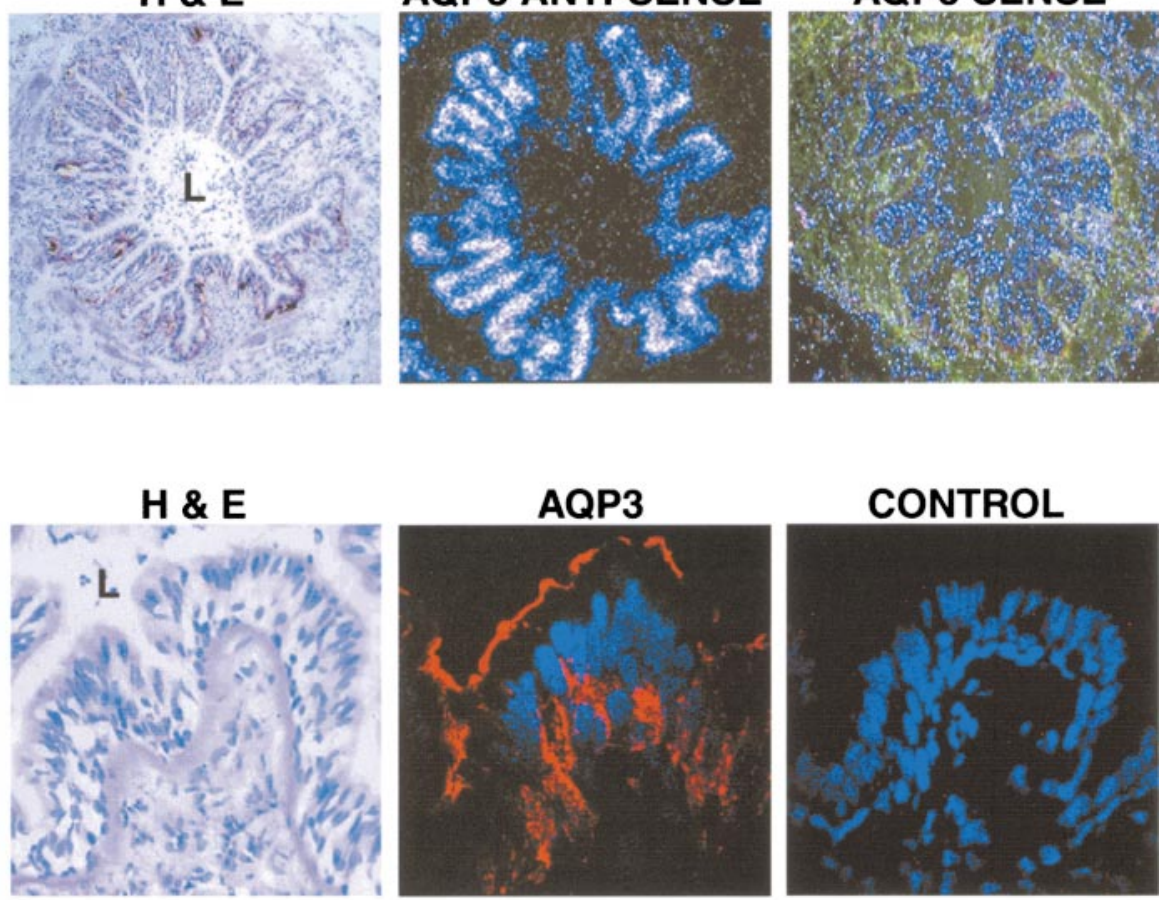

Figure 5. AQP3 expression in human pseudostratified bronchiolar epithelium. (A) In situ hybridization of AQP3 in proximal bronchioles. Consecutive cross sections of a proximal bronchiole. Left image is an H\&E brightfield; middle and right images represent sections hybridized by AQP3 antisense and sense probes, respectively. Original magnification: $\times 80$. (B) Immunostaining with ratAQP3 antibody shows AQP3 expressed in the apical membrane of columnar cells facing the lumen, as well as in the membranes of the basal cells. Original magnification: $\times 600$. $(C)$ Higher magnification $(\times 2,400)$ of section shown in $B$, with AQP3 immunostaining specific to apical and basolateral membrane of columnar cells (upper panel) and plasma membranes of basal cells (lower panel). IF images in $B$ and $C$ are $x y$ confocal scanning $(z \sim 1 \mu \mathrm{m})$ of the same field at different focal planes.
COLUMNAR CELLS

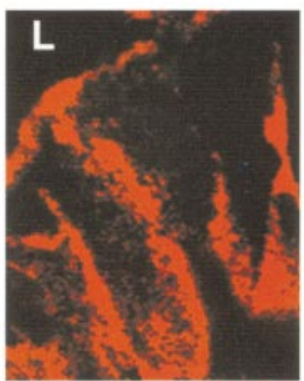

BASAL CELLS

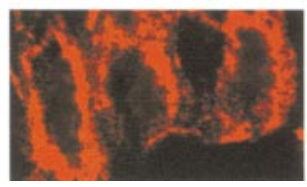

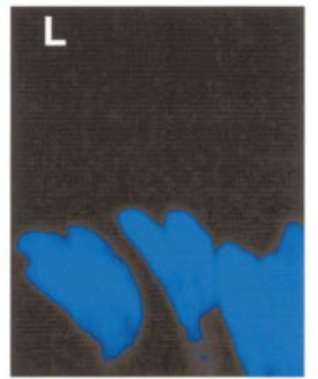

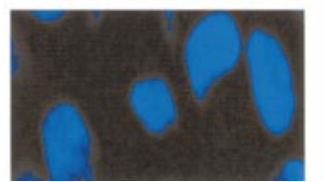


A
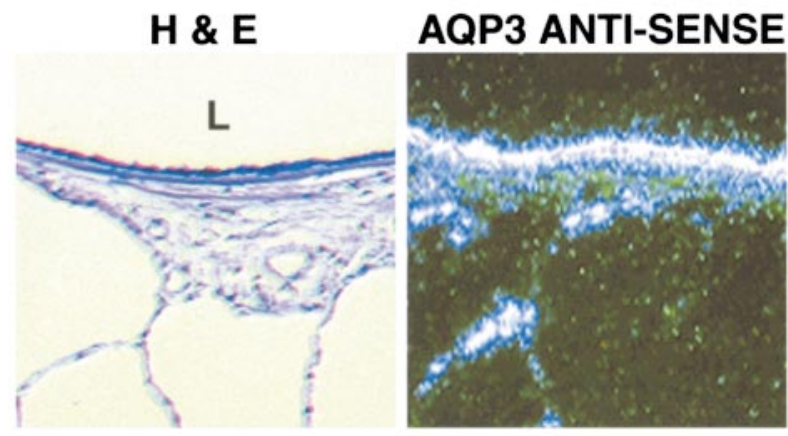

B
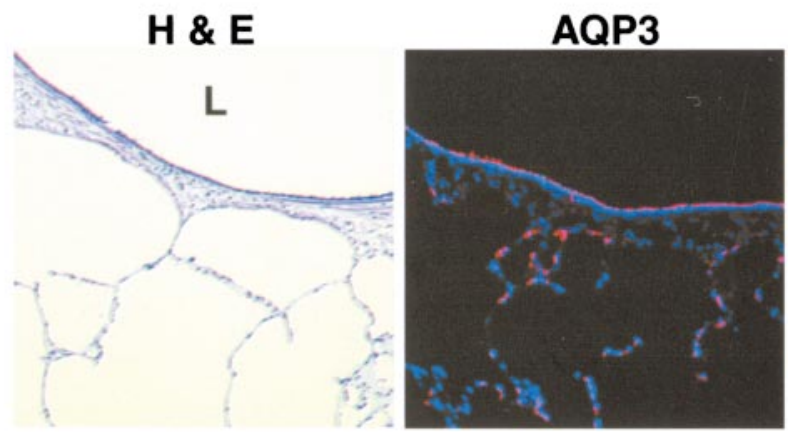

C
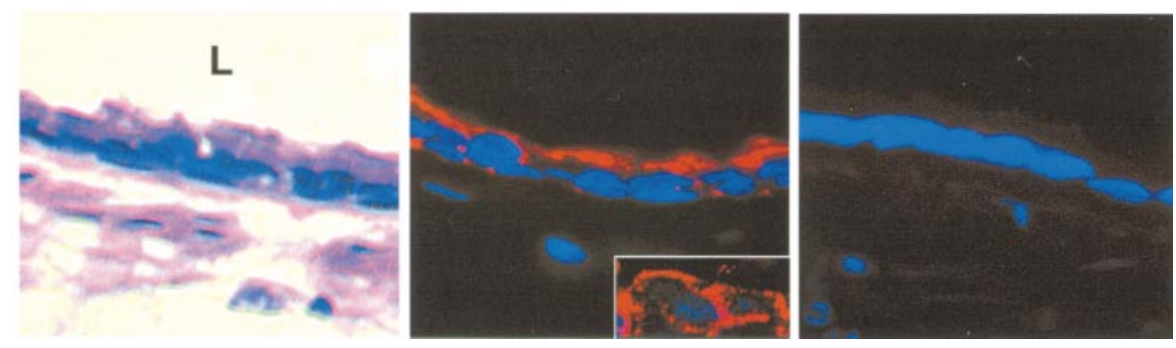

Figure 6. AQP3 expression in human simple cuboidal bronchiolar epithelium. (A) In situ hybridization for AQP3 in terminal bronchioles. Left image is an $\mathrm{H} \& \mathrm{E}$ brightfield; middle and right images represent sections hybridized by AQP3 antisense and sense probes, respectively. Original magnification: $\times 100$. (B) AQP3 immunostaining of the lumenal surface of the cuboidal epithelium (original magnification: $\times 40)$. $(C)$ Increased magnification $(\times 800)$ of images shown in $B$ to depict specific AQP3 staining in the apical membrane of the cuboidal cells (middle panel) as well as in the basolateral membranes of these cells (inset: $x y$ confocal scanning, $z \sim 1 \mu \mathrm{m}$; original magnification: $\times 1,000)$. distinct pattern, consistent with expression in type I pneumocytes (Figure 7A). AQP5 immunocytochemistry showed a similarly random, diffuse pattern of expression in alveolar cells (Figure 7B). We were unable to localize AQP5 immunoreactivity to a specific cellular surface in these alveolar cells.

AQP4 ISH also revealed a diffuse pattern of expression in the alveolar region (Figure 7C). It was difficult to determine a particular alveolar cell type that is consistent with this pattern of expression and which may suggest AQP4 expression in multiple cell types. IF studies with AQP4 antisera were not able to identify a more specific pattern of cellular expression.

ISH with an AQP3-specific riboprobe in alveoli displayed a "cornering" pattern of expression characteristic of type II pneumocytes (Figure 8A). The pattern of AQP3 immunostaining confirmed the scattered expression seen by ISH in alveolar tissue (Figure $8 \mathrm{~B}$ ). Strong immunoreactivity was observed exclusively in type II pneumocytes, as recognized by morphology and immunostaining consecu- tive sections with an anti-SP (anti-SP-C) antibody, specific for type II cells (17) (Figure 8B, right panel). Specificity was determined in all sections with nonimmune controls. Further analysis of AQP3 and SP-C immunostaining by confocal microscopy suggested that AQP3 was localized to the basolateral membrane of type II pneumocytes (Figure $8 \mathrm{C}$ ).

\section{Discussion}

The principal goal of this study was to determine the distribution of AQPs in the human airway. Our results (summarized in Table 1) describe an extensive network of AQP expression in human respiratory epithelia. We have noted both similarities and differences compared with previous studies of AQP localization in rodent airways. The interspecies differences in AQP localization may reflect differences in lung morphology, whereas the similarities likely describe the importance of lung liquid clearance in the mammalian lung. Perhaps the most unique finding of this 
A
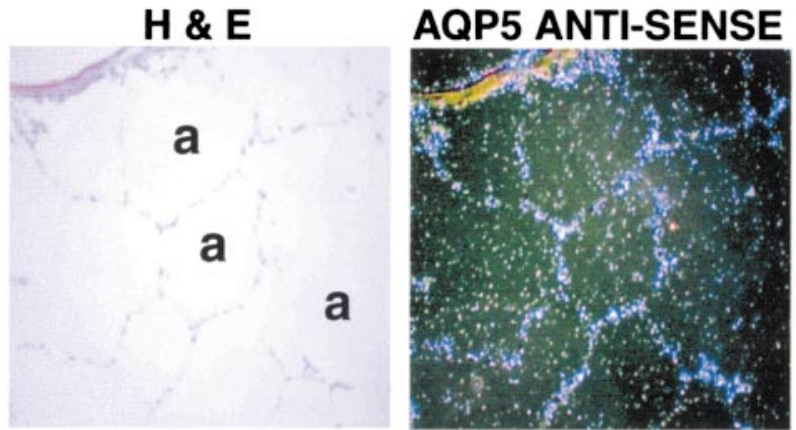

B
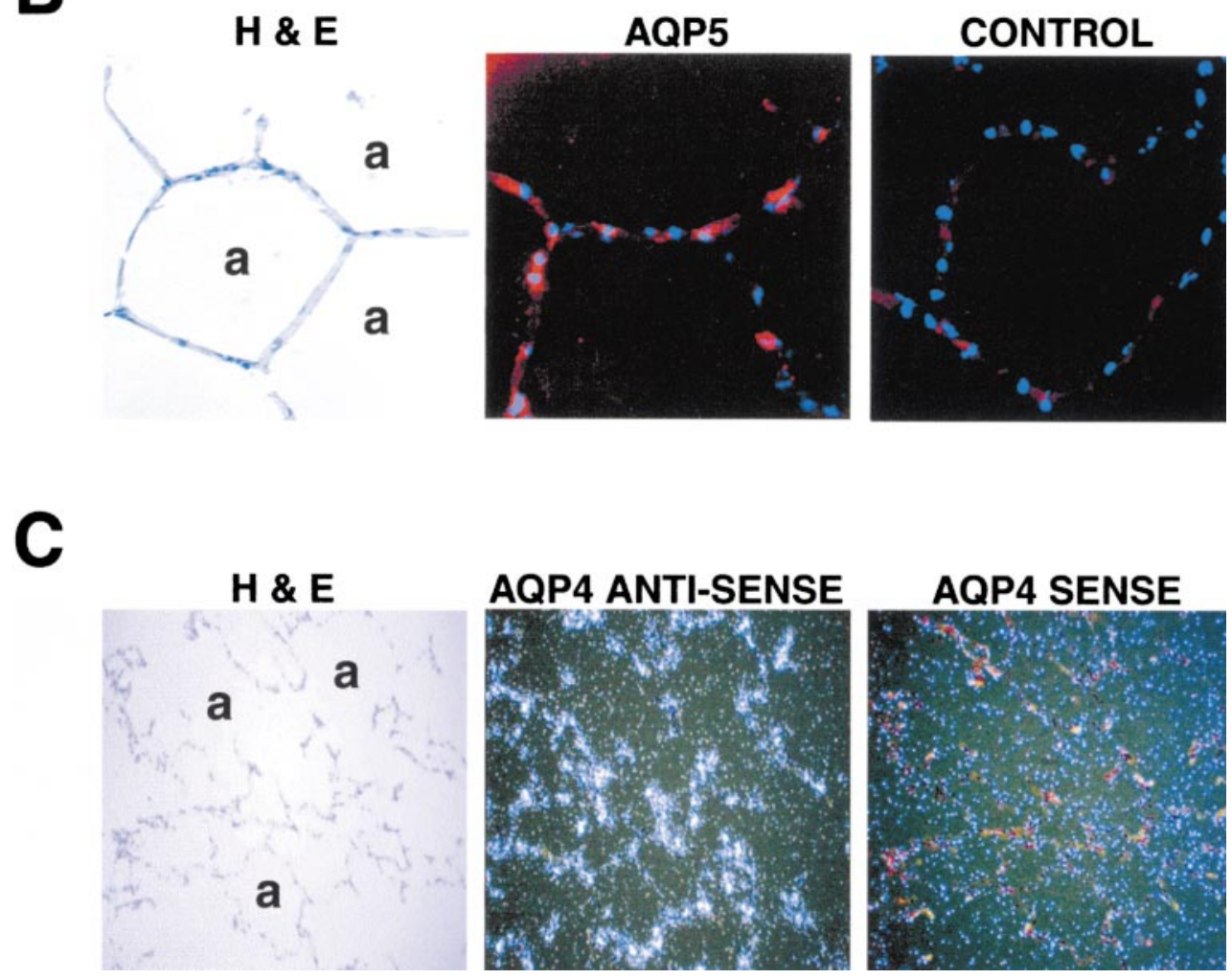

Figure 7. Expression of AQP5 and AQP4 in human alveolar epithelium. (A) In situ hybridization of AQP5 in alveoli. Left image is an H\&E brightfield; middle and right images represent sections hybridized by AQP5 antisense and sense probes, respectively. Original magnification: $\times 40$. $(B)$ AQP5 specific IF in alveolar cells. Original magnification: $\times 120$. (C) In situ hybridization for AQP4 in alveoli. Left image is an $\mathrm{H} \& \mathrm{E}$ brightfield; middle and right images represent sections hybridized by AQP4 antisense and sense probes, respectively. Original magnification: $\times 40$. Selected air spaces in this figure and Figure 8 are indicated with an a. study is the identification of high levels of AQP3 expression in lumen-facing cells of the distal airways in contrast with moderate AQP3 expression in basal cells (non-lumen facing) of the proximal airways.

Under normal conditions, insensible water losses from the nose and proximal bronchi during inspiration results in a slightly hypertonic airway surface liquid $(5,19,20)$. These proximal water losses are accelerated under tachypneic stress or during the inspiration of cold, dry air (e.g., in winter [19-21]). Measurement of the $\mathrm{P}_{\mathrm{f}}$ of cultured epithelial cells derived from the human proximal airways yielded a transepithelial $P_{f}$ of $1.7 \times 10^{-2} \mathrm{~cm} / \mathrm{s}$. (6). This value is too large to be accounted for by simple diffusion of water across the phospholipid bilayer and is consistent with the presence of water channel(s) in the apical membrane of lumenfacing cells $(7-10,13)$. AQP5 may contribute to this $P_{f}$ and the pathway for replenishment of evaporative losses and rapid restoration of proximal airway ASL to a rehydrated state. This conclusion is strengthened by two separate experimental results. First, a screen of human tracheal epithelium with a "mercury-binding region" probe identified AQP5 as the most likely water channel (59 AQP5 clones out of 101 positives). Second, ISH analysis clearly detected signal for AQP5 message in both the surface epithelium and submucosal glands of nasal and bronchial human airways. We were able to confirm AQP5 expression in human nasal but not bronchial surface epithelial membranes by IF. We speculate that this difference likely reflects the lower level of AQP5 expression in bronchial regions where evaporative water loss may be less than in nasal regions. Moreover, the studies of Matsui and colleagues in human bronchial epithelial cells demonstrated an apical membrane $P_{f}$ 


\section{A}
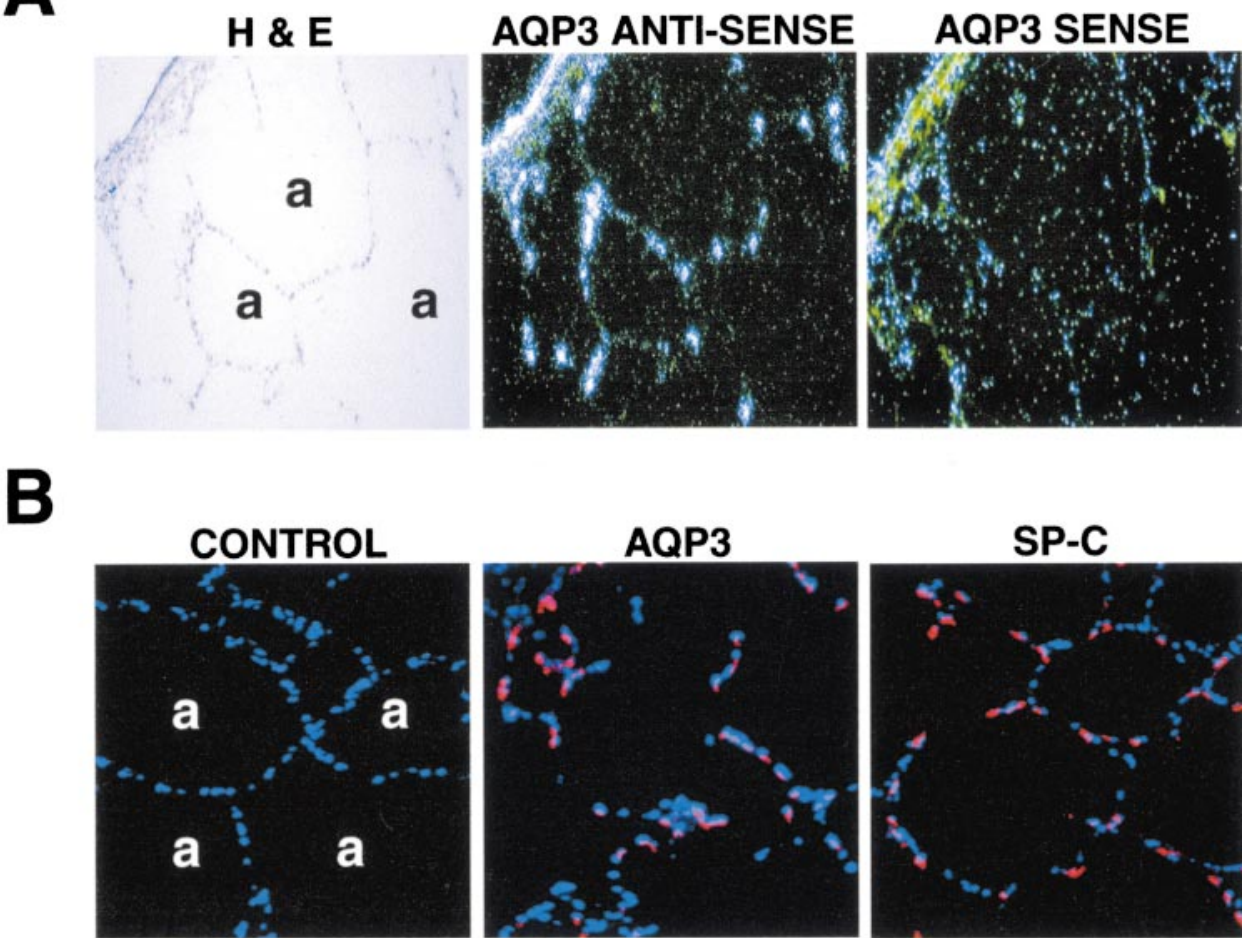

Figure 8. AQP3 expression in human alveolar epithelium. (A) In situ hybridization of AQP3 in alveoli. Left image is an $\mathrm{H} \& \mathrm{E}$ brightfield; middle and right images represent sections hybridized by AQP3 antisense and sense probes, respectively. Original magnification: $\times 40$. (B) Immunostaining with antibodies against rat-AQP3 (middle panel) and rat pro-SPC (right panel). Original magnification: $\times 100$. (C) $x y$ confocal scanning planes $(z \sim 1 \mu \mathrm{m}$; original magnification: $\times 2,000)$ with anti-AQP3 antibody (middle panel) and anti-pro-SPC antibody (right panel).
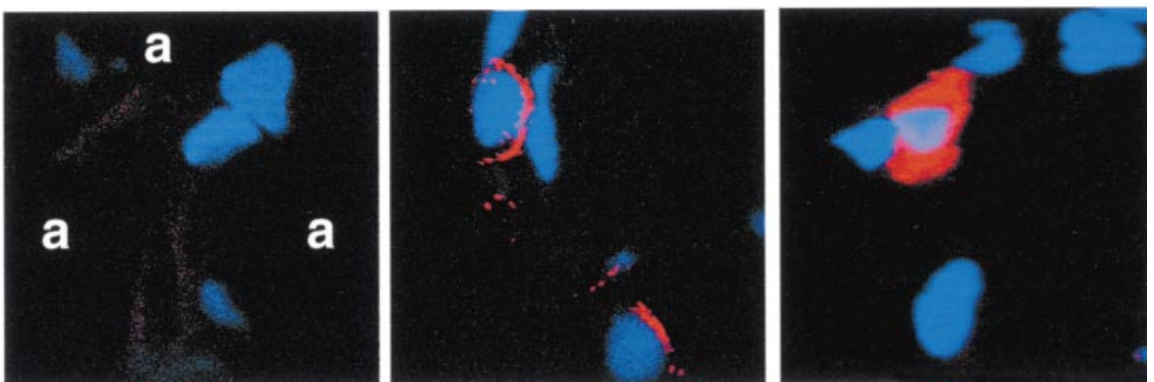

value that was only $\approx 30 \%$ sensitive to mercury (AQP5 is reported to be $\approx 60 \%$ inhibited by mercury) (6). Therefore, we cannot eliminate the possibility of another, unidentified AQP that may participate along with AQP5 to facilitate $P_{f}$ in human bronchi.

A second significant finding in human bronchial epithelial cells was the expression of AQP4. Previous studies localized AQP4 to the basolateral membrane of lumen-facing cells of the rat bronchus (14). Our study detected AQP4 by ISH in the surface epithelium of bronchial epithelia, but we were unable to determine a cellular localization using several different AQP4 antibodies. We would speculate that AQP4 is resident in the basolateral membrane, consistent with the findings in the rat bronchus. Both ISH and immunostaining studies also revealed expression of AQP4 in ciliated ducts, and specifically localized expression to the basolateral membrane of columnar cells. Thus, in certain regions of the large airways we have observed apical membrane expression of AQP5 and basolateral expression of AQP4 that may func- tion in concert to restore water from the submucosal vasculature and protect the epithelia from evaporative dehydration.

AQP3 was localized to basal cells of the pseudostratified nasal and bronchial epithelia. This localization correlates well with studies from rat lung (14). AQP3 expression in basal cells may account for the rapid shrinkage and water efflux in this cell type in response to subepithelial osmotic gradients (6). AQP3 has been termed an "aquaglyceroporin" (like AQP7 and AQP9) because it is capable of transporting glycerol and urea as well as transporting water (22-25). A role for AQP3 as a solute channel and the relevance of this function in human bronchial epithelial physiology remains to be established, but may be especially important in basal cells that do not face the airway lumen. More functional studies are necessary to understand fully the role of AQP3 in this region of the human airways and its contribution to lung disease.

We also determined the expression of AQP in proximal airway submucosal glands. Although the tonic contribu- 
TABLE 1

\begin{tabular}{|c|c|c|c|c|c|c|}
\hline \multirow{2}{*}{$\begin{array}{l}\text { Airway } \\
\text { Epithelium }\end{array}$} & \multicolumn{2}{|r|}{ AQP5 } & \multicolumn{2}{|r|}{ AQP4 } & \multicolumn{2}{|r|}{ AQP3 } \\
\hline & ISH & IF & ISH & IF & ISH & IF \\
\hline \multicolumn{7}{|l|}{ Nose } \\
\hline Superficial & + & $\mathrm{AM}$ of $\mathrm{CC}(++)$ & ND & ND & - & $\mathrm{BLM}$ of $\mathrm{BC}(++)$ \\
\hline Glands/ducts & + & $\mathrm{AM}$ of $\mathrm{GC}(++)$ & ND & ND & - & BLM of BC $(+)$ \\
\hline \multicolumn{7}{|l|}{ Bronchus } \\
\hline Superficial & + & ND & + & ND & + & Membranes of BC $(++)$ \\
\hline Glands/ducts & + & $\begin{array}{c}\text { AM of CC (ducts) }(++) \\
\text { AM of GC }(+)\end{array}$ & + & BLM of CC (ducts) ( \pm ) & ND & ND \\
\hline \multicolumn{7}{|l|}{ Bronchiole } \\
\hline Pseudostratified & ND & ND & ND & ND & + & $\begin{array}{c}\text { AM/BLM of CC }(++) \\
\text { Membranes of BC }(++)\end{array}$ \\
\hline Simple-cuboidal & ND & ND & ND & ND & + & $\mathrm{AM} / \mathrm{BLM}$ of $\mathrm{CuC}(++)$ \\
\hline Alveolus & + & Type I cells $(+)$ & + & ND & + & BLM of Type II cells $(++)$ \\
\hline
\end{tabular}

The data summarize the results from two or three independent experiments using multiple tissue sections, each from a different donor. AM: apical membrane, BLM: basolateral membrane, CC: columnar cell, BC: basal cell, GC: gland acinus cell, CuC: bronchiolar cuboidal cell, +: specific ISH signal, ND: signal was below detectable level, $-:$ not determined. A semiquantitative analysis of the IF signal is described as negative or low $( \pm)$, moderate $(+)$, or strong $(++)$ intensity.

tion of submucosal gland secretions to the ASL is not yet clearly defined, it is likely to be complex. Acini primarily secrete liquid, distal ducts may modify the acinar secretions and may decrease tonicity, and ciliated ducts propel the liquid out to the lumen. In acinar portions of the glands, we found robust AQP5 expression localized to the apical membrane of acinar cells. AQP5 has been localized to this same barrier in rat immunolocalization studies, as well as to the acinar cells of rat parotid, submandibular, and lachrymal glands $(14,18,26)$. Functional data consistent with a role of AQP5 in gland secretions have been reported from the AQP5 knockout mouse model, which has glandular secretions that are reduced in volume by $60 \%$ and show have a hypertonic saliva with elevated $\mathrm{Na}, \mathrm{Cl}$, and K levels (27). We also found strong expression of AQP4 in acini and speculate it localizes to basolateral membranes, as has been shown in rat airway glands (14). These observations are consistent with the hypothesis that submucosal glands produce an isotonic solution (acini secrete ions and water) and that water flow is mediated by AQP4 and AQP5 in series in acinar cells (5).

AQP expression in human small airways (proximal and terminal bronchioles) revealed a surprising finding. Both ISH and IF studies detected high levels of expression of $\mathrm{AQP} 3$ but not AQP5 or AQP4. In contrast to larger airways, expression of AQP3 was not restricted to the membranes of basal cells but was also found in the apical membrane of columnar cells of psuedostratified bronchiolar epithelium, as well as in both membranes of cuboidal cells of the terminal bronchioles. This expression pattern for AQP3 in human small airways does not appear to have a similar counterpart in animal models. In various animal models, AQP3 was found only in basal cells of multilayered epithelia, large airways $(14,22,28)$, gastrointestinal tract $(13,22,24)$, kidney and urinary tract $(7,22)$, and skin (22).

The presence of AQP3 in this peripheral region is predicted to confer a robust volume absorptive capacity to this epithelium. The qualitative magnitude of AQP3 expression observed in our studies, as demonstrated by the intensity of both ISH and IF, is suggestive of a high membrane density of AQP3 and is consistent with functional studies describing a high membrane $\mathrm{P}_{\mathrm{f}}$ of distal airways measured in microperfusion studies (8). In these noncartilagenous, aglandular airway segments, ASL is postulated to be transported axially from peripheral to central lung regions $(5,29)$. We speculate that net absorption of salt and water is highest in distal segments, given the volume load imposed on airways during proximal migration from the distal sources of liquid secretion, perhaps even including the alveoli (29).

Although our primary objective was airway epithelial water transport, we were able to make certain observations about AQP expression in the human alveolar region. Previous studies in rodents have described expression of AQP5 in alveolar cells, localized to the apical membrane of type I pneumocytes in the rat lung (14). We also found AQP5 expressed in type I cells of the human lung by ISH and IF. In contrast to rodent studies, however, we found evidence for both AQP4 and AQP3 in the distal human lung. The ISH AQP4 signal was striking in the alveolar region with a pattern that could not be unambiguously interpreted as specific for either type I or type II cells. We speculate AQP4 is expressed at least in type I cells because (1) in all lung cell types studied, AQP5 and AQP4 have been localized to the same cell type; and (2) ISH indicates a large percentage of pneumocytes expressing AQP4, greater than can be accounted for by type II cells alone. ISH patterns for AQP3 were strongly characteristic of expression in cuboidal type II pneumocytes. We were able to confirm the mRNA expression pattern by IF showing AQP3 protein expression in a "cornering" pattern, consistent with type II cell distribution. An antibody for the rat pro-SP-C (17) showed an expression pattern that was nearly identical to that observed with the various AQP3 antisera studied. Thus, we conclude that AQP3 localizes to type II pneumocytes in the human lung.

At birth, or after edematous conditions, water absorption may be induced by increasing the expression level of 
several AQPs $(2,4,30,31)$. It is clear that under many different physiologic conditions, AQPs may play a role in transepithelial water transport to regulate the volume and osmolarity of the liquid on the alveolar surface. The role that type I and II pneumocytes play in mediating alveolar water flow is not yet well understood $(10,30)$. Our data suggest that AQP4 and AQP5 are situated in the appropriate membranes to facilitate transepithelial water movement across type I cells. AQP3 expressed in type II cells could modify the alveolar surface liquid by altering either $\mathrm{P}_{\mathrm{f}}$ or solute transport, but AQP3 localization to the basolateral membrane would also require the presence of another AQP in the apical membrane of type II cells.

In summary, we have identified the distribution patterns for AQPs 3, 4, and 5 in the human nasal and lung regions and found both similarities and differences to comparable studies performed in animal models. We have demonstrated expression of AQP5 in the surface epithelium of large airways where a functional role for AQPs has been postulated for replenishment of insensible water loss. Because we also showed the presence of AQP4 in the basolateral membrane of this airway region, it is reasonable to predict that these two AQPs may function in a coordinated manner to achieve transepithelial $\mathrm{P}_{\mathrm{f}}$. The extensive distribution of AQP3 expression in small and distal airways is perhaps the most striking finding of this study. We speculate that in this airway region, AQP3 may be important in dealing with the large volume absorption that occurs as a result of the axial movement of water from the alveolus. Finally, we have also shown expression of AQPs 3, 4, and 5 in the human alveolar region, consistent with the requirement for transcellular water movement as well as perhaps AQP3-specific functions in type II cells. The identification of discrete AQP distribution throughout the human airways is an initial step toward an understanding of the mechanistic physiology of intrapulmonary surface liquid flow and its potential for dysfunction in disease.

Acknowledgments: The authors thank the UNC cystic fibrosis morphology core, Ms. Kim Burns, and Ms. Tracy Bartolotta for technical assistance with tissue preparation and sectioning. The authors also thank Dr. Lori Rochelle (UNC) and Dr. Dong Chen Li (Louisiana State University, Shreveport, LA) for expert advice and guidance with in situ protocols. The authors also thank Dr. Mark Knepper (NIH, Betheseda, MD) and Dr. Jeff Whittset (University of Cincinnati, Cincinnati, $\mathrm{OH}$ ) for the generous contribution of antibodies. The authors are also appreciative to Ms. Lisa Brown (UNC) for assistance with manuscript preparation and image formatting. This work was supported in part by grants to two authors (R.C.B. and S.E.G.) from the NIH (grants HL62564 and HL34322).

\section{References}

1. Wilumsen, N. J., C. W. Davis, and R. C. Boucher. 1994. Selective response of human airway epithelia to luminal but not serosal solution hypertonicity. J. Clin. Invest. 94:779-787.

2. Umenishi, F., E. P. Carter, B. Yang, B. Oliver, M. A. Matthay, and A. S. Verkman. 1996. Sharp increase in rat lung water channel expression in the perinatal period. Am. J. Respir. Cell Mol. Biol. 15:673-679.

3. Carter, E. P., F. Umenishi, M. A. Matthay, and A. S. Verkman. 1997. Developmental changes in water permeability across the alveolar barrier in perinatal rabbit lung. J. Clin. Invest. 100:1071-1078.

4. King, L. S., S. Nielsen, and P. Agre. 1997. Aquaporins in complex tissues: I. Developmental patterns in respiratory and glandular tissues of rat. Am. J. Physiol. 273:C1541-C1548.
5. Boucher, R. C. 1999. Molecular insights into the physiology of the "thin film" of airway surface liquid. J. Physiol. 516:631-638.

6. Matsui, H., C. W. Davis, R. Tarran, and R. C. Boucher. 2000. Osmotic water permeabilities of cultured, well-differentiated normal and cystic fibrosis airway epithelia. J. Clin. Invest. 105:1419-1427.

7. King, L. S., M. Yasui, and P. Agre. 2000. Aquaporins in health and disease. Mol. Med. Today 6:60-65.

8. Verkman, A. S., M. A. Matthay, and Y. Song. 2000. Aquaporin water channels and lung physiology. Am. J. Physiol. 278:L867-L879.

9. Verkman, A. S., and A. K. Mitra. 2000. Structure and function of aquaporin water channels. Am. J. Physiol. 278:F13-F28.

10. King, L. S., S. Nielsen, and P. Agre. 2000. Respiratory aquaporins in lung inflammation. Am. J. Respir. Cell Mol. Biol. 22:8-10.

11. Folkesson, H. G., M. A. Matthay, A. Frigeri, and A. S. Verkman. 1996. Transepithelial water permeability in microperfused distal airways. J. Clin. Invest. 97:664-671.

12. Carter, E. P., M. A. Matthay, J. Farinas, and A. S. Verkman. 1996. Transalveolar osmotic and diffusional water permeability in intact mouse lung measured by a novel surface fluorescence method. J. Gen. Physiol. 108: 133-142.

13. Lee, M. D., L. S. King, and P. Agre. 1997. The aquaporin family of water channel proteins in clinical medicine. Medicine (Baltimore) 76:141-156.

14. Nielsen, S., L. S. King, B. M. Christensen, and P. Agre. 1997. Aquaporins in complex tissues: II. Subcellular distribution in respiratory and glandular tissues of rat. Am. J. Physiol. 273:C1549-C1561.

15. Terris, J., C. A. Ecelbarge, D. Marples, M. A. Knepper, and S. Nielsen. 1995. Distribution of aquaporin-4 water channel expression within rat kidney. Am. J. Physiol. 269:F775-F785.

16. Ecelbarger, C. A., J. Terris, G. Frindt, M. Echevarria, D. Marples, S. Nielson, and M. A. Knepper. 1995. Aquaporin-3 water channel localizaiton and regulaiton in rat kidney. Am. J. Physiol. 269:F663-F672.

17. Vorbroker, D. K., C. Dey, T. E. Weaver, and J. A. Whitsett. 1992. Surfactant protein $\mathrm{C}$ precursor is palmitoylated and associates with subcellular membranes. Biochim. Biophys. Acta 1105:161-169.

18. Raina, S., G. M. Preston, W. B. Guggino, and P. Agre. 1995. Molecular cloning and characterization of an aquaporin cDNA from salivary, lacrimal and respiratory tissues. J. Biol Chem. 270:1908-1912.

19. Man, S. F. P., G. K. Adams, and D. F. Proctor. 1979. Effects of temperature, relative humidity and mode of breathing on canine airway secretions. $J$. Appl. Physiol. 46:205-210.

20. Freed, A. N., and M. S. Davis. 1999. Hyperventilation with dry air increases airway surface fluid osmolality in canine peripheral airways. Am. J. Respir. Crit. Care Med. 159:1101-1107.

21. Gilbert, I. A., J. M. Fouke, and E. R. MacFadden. 1987. Heat and water flux in the intrathoracic airways and exercise-induced asthma. J. Appl. Physiol. 64:2167-2174.

22. Matsuzaki, T., T. Suzuki, H. Koyama, S. Tanaka, and K. Takata. 1999. Water channel protein AQP3 is present in epithelia exposed to the environment of possible water loss. J. Histochem. Cytochem. 47:1275-1286.

23. Johnston, H., I. Koukoulas, K. Jeyaseelan, A. Armugam, L. Earnest, R. Baird, N. Dawson, T. Ferraro, and E. M. Wintour. 1999. Ontogeny of aquaporins 1 and 3 in ovine placenta and fetal membranes. Placenta 21:88-99.

24. Ma, T., Y. Song, B. Yang, A. Gillespie, E. J. Carlson, C. J. Epstein, and A. S. Verkman. 2000. Nephrogenic diabetes insipidus in mice lacking aquaporin-3 water channels. Proc. Natl. Acad. Sci. USA 97:4386-4391.

25. Kishida, K., H. Kuriyama, T. Funahashi, I. Shimomura, S. Kihara, N. Ouchi, M. Nishida, H. Nishizawa, M. Matsuda, M. Takahashi, K. Hotta, T. Nakamura, S. Yamashita, Y. Tochino, and Y. Matsuzawa. 2000. Aquaporin adipose, a putative glycerol channel in adipocytes. J. Biol. Chem. 275:2089620902.

26. Funaki, H., T. Yamamoto, Y. Koyama, D. Kondo, E. Yaoita, K. Kawasaki, H. Kobayashi, S. Sawaguchi, H. Abe, and I. Kihara. 1998. Localization and expression of AQP5 in cornea, serous salivary glands, and pulmonary epithelial cells. Am. J. Physiol. 275:C1151-C1157.

27. Ma, T., Y. Song, A. Gillespie, E. J. Carlson, C. J. Epstein, and A. S. Verkman. 1999. Defective secretion of saliva in transgenic mice lacking aquaporin-5 water channels. J. Biol. Chem. 274:20071-20074.

28. Frigeri, A., M. A. Gropper, C. W. Turck, and A. S. Verkman. 1995. Immunolocalization of the mercurial-insensitive water channel and glycerol intrinsic protein in epithelial cell plasma membranes. Proc. Natl. Acad. Sci. USA 92:4328-4331.

29. Matsui, H., S. H. Randell, S. W. Perett, C. W. Davis, and R. C. Boucher. 1998. Coordinated clearance of periciliary liquid and mucus from airway surfaces. J. Clin. Invest. 102:1125-1131.

30. King, L. S., S. Nielsen, and P. Agre. 2000. Aquaporins and the respiratory system: advice for a lung investigator. J. Clin. Invest. 105:15-16.

31. Towne, J. E., K. S. Harrod, C. M. Krane, and A. G. Menon. 2000. Decreased expression of aquaporin (AQP)1 and AQP5 in mouse lung after acute viral infection. Am. J. Respir. Cell Mol. Biol. 22:34-44. 